KirkhaM, D. S. (1957). J. gen. Microbiol. 17, 120-134

\title{
Studies of the Significance of Polyphenolic Host Metabolites in the Nutrition of Venturia inaequalis and Venturia pirina
}

\author{
BY D. S. KIRKHAM
}

East Malling Research Station, Kent

\begin{abstract}
SUMMARY : Extracts of the polyphenolic fractions of the water-soluble metabolites (that is, the complex mixtures of plant phenols extracted by ethyl acetate) were prepared from apple and pear varieties characterized by different degrees of resistance to the scab pathogens. Qualitative differences were chiefly interspecific and extracts of resistant varieties did not contain major components lacking in those of lessresistant varieties of the same species. Cultural reactions of distinct clones of each pathogen to the extracts, in the presence of various basal media, were observed. Growth and sporulation were inhibited independently by extracts of less-resistant as well as resistant host varieties. The clones were not equally susceptible, those of Venturia inaequalis showing relationships between inhibition of sporulation by host polyphenols and their varietal host ranges. Fluctuations in pathogenicity of a clone of $V$. pirina during storage in culture with periodic re-isolation from Williams pear were reflected in its reactions to the extracts. Both pathogens were capable of decomposing the polyphenols. The results suggested that qualitative and quantitative variations in the polyphenolic host metabolites, including differences in their relative proportions, in relation to nitrogenous and other nutritional factors, are of potential significance in the determination of pathogenicity and varietal resistance.
\end{abstract}

A study of distinct clones of Venturia inaequalis (Cke.) Wint. and V. pirina Aderh., the causal fungi of apple and pear scab, respectively (Kirkham, 1957) has shown that interspecific and interclonal differences in pathogenicity and host range are not necessarily associated with corresponding differences in nutritional requirements. Clones of $V$. inaequalis which were pathogenic on the greatest number of apple varieties were the most stable in artificial culture, but no other indications were obtained of relationships between the reactions of either pathogen in natural and artificial environments. These observations, and the work of Wiltshire (1915), Johnstone (1931) and Rudloff (1934), point to the importance of considering all groups of host metabolites, including the plant phenols, as factors in the metabolism of Venturia species and in the determination of their host relations. Bradfield \& Flood (1949) showed that the main qualitative differences between the water-soluble constituents of apple and pear shoots lie in the polyphenolic fractions (that is, the complex mixtures of plant phenols extractable by ethyl acetate). In the present communication polyphenolic fractions of apple and pear varieties characterized by different degrees of resistance are compared, and the results of cultural studies of the possible significance of these and other host metabolites in the nutrition of the pathogens are given. Some results of this study have already been briefly reported (Kirkham, 1954). 


\section{METHODS}

The first series of extracts was prepared from young leaves of the apple varieties Cox's Orange Pippin and Miller's Seedling on Malling II rootstocks, and of the pear varieties Williams' Bon Chrétien and Conference on Quince A rootstocks. Young leaves were defined as all those younger than, and including the first fully unrolled leaf, below a shoot tip; the polyphenolic fractions were obtained by direct extraction of the macerated leaves with ethyl acetate (Bradfield in 1951). A second series of extracts was prepared by the same method from mature leaves of the same varieties (mature leaves being defined as those of maximum size on a shoot). Considerable enzymic browning of the pulp, particularly of the pear material, occurred during extraction and resulted in some decrease in yield. Later, a third series of extracts was prepared from young leaves of the same varieties when an extraction method similar to that described by Bradfield \& Flood (1949) was used. Each sample of leaf material was macerated in aqueous methanol $(80 \%, v / v)$, and the pulp then thoroughly washed with fresh solvent until the washings were colourless. Most of the methanol was removed by distillation under reduced pressure, and the residual aqueous solution separated from the green chlorophyll sludge by centrifugation. This solution was then extracted with ethyl acetate to separate the polyphenolic fraction from the other water-soluble leaf constitutents. Only very slight browning of the apple- and pear-leaf pulp was observed. The three extracts prepared from each variety were numbered $\mathbf{1}$, 2 and 3. Pure samples of phloridzin, arbutin, chlorogenic acid, isochlorogenic acid and the polyphenolic fraction of the rootstock SV 411 were supplied by the Biochemistry Section of East Malling Research Station. Chromatograms were run by upward displacement on Whatman no. 1 paper at $21^{\circ}$ using as solvent mixture $n$-butanol/acetic acid/water (63/10/27, v/v; Campbell, Work \& Mellanby, 1951). After solvent removal the chromatograms were examined under ultraviolet light before and after treatment with ammonia, and were subsequently sprayed with diazotized $p$-nitroaniline in sodium acetate solution (Bradfield, 1951; private communication).

Six clones of Venturia inaequalis and five of $V$. pirina (described in detail by Kirkham, 1957) were used in these studies. The apple or pear variety sources of the Venturia clones, arranged in increasing order of field-resistance, and their host ranges are indicated in Table 1. During the work the clones of Venturia spp. were stored under paraffin oil and were periodically re-isolated as single conida either from the stock cultures (re-isolation 2) or from artificially inoculated shoots (re-isolations 1 and 3 ). The time intervals between primary isolation (P.I.) from field-infected material and the re-isolations were as follows: P.I.-re-isolation 1, 24 months (clones E1 and D2) and 12 months for the remaining clones; re-isolations 1-2, 11 months; 2-3, 7 months.

The clones of Venturia spp. were grown on filter-paper cylinders standing in filter-sterilized liquid media; degree of sporulation was estimated by a turbidimetric method in which the readings were directly proportional to the number of conidia produced (Kirkham, 1956). The cultures were incubated to 
Table 1. Varietal sources and host ranges of distinct clones of Venturia inaequalis and $\mathrm{V}$. pirina

\begin{tabular}{|c|c|c|c|}
\hline Organism & Clone & $\begin{array}{l}\text { Apple (for } V . \text { inaequalis) or pear } \\
\text { (for } V \text {. pirina) variety source* }\end{array}$ & $\begin{array}{c}\text { Extent of host } \\
\text { range. } \dagger \text { Number of } \\
\text { varieties attacked }\end{array}$ \\
\hline$V$. inaequalis & $\begin{array}{l}\text { A26 } \\
\text { A6 } \\
\text { A7 } \\
\text { A20 } \\
\text { E1 }\end{array}$ & $\begin{array}{l}\text { Cox's Orange Pippin } \\
\text { Worcester Pearmain } \\
\text { Worcester Pearmain } \\
\text { Laxton's Superb } \\
\text { Edward VII }\end{array}$ & $\begin{array}{l}\mathbf{3} \\
\mathbf{5} \\
\mathbf{6} \\
\mathbf{7} \\
\mathbf{8}\end{array}$ \\
\hline$V \cdot$ pirina & $\begin{array}{l}\text { P16 } \\
\text { P17 } \\
\text { P6 } \\
\text { D2 } \\
81^{\prime}\end{array}$ & $\begin{array}{l}\text { Williams' Bon Chrétien } \\
\text { Williams' Bon Chrétien } \\
\text { Laxton's Superb } \\
\text { Durondeau } \\
\text { Conference }\end{array}$ & $\begin{array}{l}\mathbf{6} \\
\mathbf{5} \\
\mathbf{7} \\
\mathbf{6} \\
\mathbf{3}\end{array}$ \\
\hline
\end{tabular}

* Varieties arranged in increasing order of field resistance.

$\dagger$ Number of sporulating lesion reactions resulting from inoculation of nine apple varieties with each clone of $V$. inaequalis and eight pear varieties with each clone of $V$.pirina.

maturity at $18^{\circ}$, that is until it seemed that sporulation had reached a maximal value in the treatment. Growth was visually assessed in the following categories: $0=$ none or trace; $1=$ thin and inhibited; $2=$ normal but suboptimal; $\mathbf{3}=$ optimal. The polyphenolic host-metabolites were added to and dissolved in various basal media (at $\mathrm{pH} \mathrm{5 \cdot 6)}$ immediately before sterilization by filtration. Malt-extract $(10 \%, w / v)$ medium, a partially defined medium and modifications of the latter were used as basal media. ' $N C$ ' refers to a partially defined medium of the following composition: glucose, $1.5 \mathrm{~g}$.; enzymic digest of casein $0.35 \mathrm{~g}$.; thiamine $30 \mu \mathrm{g}$.; $\mathrm{MgSO}_{4} .7 \mathrm{H}_{2} \mathrm{O} \mathrm{0.05} \mathrm{g}$.; $\mathrm{KH}_{2} \mathrm{PO}_{4} 0.15 \mathrm{~g}$.; trace elements as used by Leben \& Keitt (1948); all in $100 \mathrm{ml}$. distilled water. Variations in the composition of this medium are indicated, for example: $\frac{1}{3} \mathrm{NC}=$ casein digest at one-third of the concentration above; $\mathrm{N3C}=$ glucose at three times the normal concentration; $\mathrm{NC} .20 \mathrm{~T}=$ trace elements at twenty times the normal concentration. The media also contained traces of malt-extract from the unwashed inoculum and $\mathrm{KCl}$ resulting from the adjustment of $\mathrm{pH}$ value.

Each treatment was applied in duplicate and the turbidimetric estimate of degree of sporulation expressed as the geometric mean of a pair of observations. Two means differed significantly ( $5 \%$ level of significance) when their ratio exceeded $1 \cdot 45$.

\section{RESULTS}

\section{Comparison of polyphenolic-fraction extracts of resistant and less resistant varieties of apple and pear}

Miller's Seedling and Cox's Orange Pippin "were compared as examples of highly scab-resistant and less-resistant apple varieties, respectively, and Conference and Williams' Bon Chrétien as resistant and less-resistant pear varieties. The complexity of the three extracts prepared from each variety ( $2 \%$ aqueous solutions) is illustrated by the twelve chromatograms shown in 
Pl. 1, fig. 1. The most outstanding differences were those between the apple and pear extracts, as noted by Bradfield \& Flood (1949). The major component of the apple fractions is phloridzin (3); the major components of the pear fractions are arbutin (1), isochlorogenic acid (5) and chlorogenic acid (2) which also occurs as a minor constituent of the apple extracts. The aglycones phloretin (4) and hydroquinone (6) of phloridzin and arbutin, respectively, were present in the first and second series of extracts, probably as artefacts because of the extraction method used.

It is clear that the major components of the polyphenolic fractions of resistant and less-resistant varieties of apple and pear, and of young and mature leaves, are the same. There are, however, indications of quantitative differences and of differences between the relative proportions of these components. Chlorogenic acid was present at higher concentrations in the Miller series than in the Cox series, and extracts of mature leaves contained more than those of young leaves. The Conference fractions contained more arbutin, chlorogenic acid and isochlorogenic acid than the Williams fractions, with the exception that there was more isochlorogenic acid in Williams 3 than in Conference 3. The ratios between the amounts of chlorogenic acid and isochlorogenic acid in each pear extract appeared to differ, being probably higher, for example, in Conference 3 than in Conference 1. Qualitative as well as quantitative differences were apparent between minor components. Preliminary evidence indicates the presence of further depside-like compounds in pear, of which there were more in Williams than in Conference. The Miller extracts contained more compounds than the Cox extracts and young leaves contained more polyphenolic compounds than mature leaves.

It is now known that the extraction techniques used were not exhaustive and that preferential extraction of some compounds probably occurred. Thus comparison of total yields of polyphenolic fraction extracts with weights of fresh material was not possible, and the quantitative variations described above cannot be regarded as definite indications of differences between varieties. It was observed however that the Miller 3 yield (per unit fresh weight of leaves) was considerably higher than that of $\operatorname{Cox} 3$ and it is therefore possible that the Miller leaf-sample contained more phloridzin and chlorogenic acid than the Cox leaf-sample.

The activity of extracts cannot be related to the major components alone owing to the qualitative variation among the minor components, and the significance of single compounds must be assessed with care owing to possible synergistic effects between them in mixtures.

\section{Reactions of the pathogenic Venturia spp. to polyphenolic host-metabolites}

Table 2 shows that polyphenolic host-metabolites inhibited sporulation and to a lesser extent growth of the pathogens in the NC basal medium. The clones were not equally susceptible to this inhibition but, excepting the reactions of Venturia pirina clone D2, extracts of resistant and less-resistant varieties, showed similar activities. This observation supports the chemical evidence of similarities between the extracts and does not suggest the 


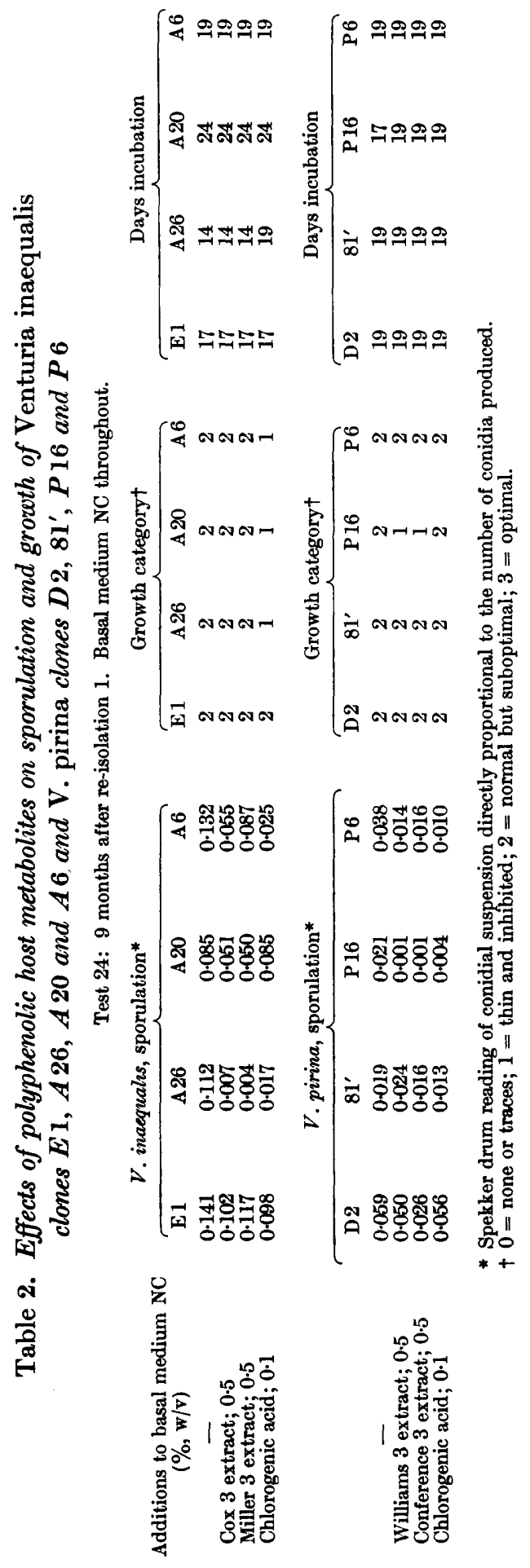


occurrence of resistance factors which are lacking in less-resistant varieties such as Cox's Orange Pippin and Williams' Bon Chrétien. The four clones of $V$. inaequalis showed relationships between their host varietal ranges (Table 1) and their susceptibility to inhibition. Thus clone A 26, which had the narrowest host range, was the most susceptible and clone $\mathrm{E} 1$, isolated from the resistant variety Edward VII and having the widest host range, was the least inhibited. No such relationships were observed within the clones of $V$. pirina. The results suggest there may be differences in the significance of polyphenolic host-metabolites in the metabolism of the two pathogens.

Chlorogenic acid was a highly active component of the extracts. Its inhibitory effects at $0.1 \%(\mathrm{w} / \mathrm{v})$ closely followed those of the extracts, being sometimes rather more and sometimes rather less active than the extracts at $0.5 \%$. A further test gave some indication that a mixture of chlorogenic acid and isochlorogenic acid was more active against E1 than either compound alone at the same concentration. This indication of synergism between the known depsides as toxic factors indicates the potential importance of any variation in the relative proportions of the polyphenolic host-metabolites under natural conditions.

Table 3. Inhibition of Venturia inaequalis clones $\mathrm{E} 1$ and A 26, by the polyphenolic fraction of the apple rootstock SV 411

Test 23: basal medium NC throughout.

\begin{tabular}{|c|c|c|}
\hline \multirow{2}{*}{$\begin{array}{c}\text { Additions to } \\
\text { basal medium NC } \\
(\%, w / v)\end{array}$} & \multicolumn{2}{|c|}{ Sporulation } \\
\hline & E 1 & A26 \\
\hline 一 & $0 \cdot 214$ & 0.269 \\
\hline SV 4.11 extract & $0 \cdot 174$ & 0.044 \\
\hline SV 411 extract; $2 \cdot 0$ & 0.001 & 0.001 \\
\hline SV 4.11 extract; 5.0 & $<0.001$ & $<0.001$ \\
\hline
\end{tabular}

\begin{tabular}{|c|c|}
\hline \multicolumn{2}{|c|}{ Growth categor } \\
\hline E 1 & A26 \\
\hline 2 & 2 \\
\hline 2 & 1 \\
\hline 1 & 1 \\
\hline 0 & $\mathbf{0}$ \\
\hline
\end{tabular}

$\overbrace{\text { E1 }}^{\text {Days incubation }} \begin{array}{cc}\text { A26 } \\ 25 & 32 \\ 25 & 32 \\ 29 & 32 \\ 29 & 32\end{array}$

The effects of increasing the amount of a host extract in medium NC, on Venturia inaequalis are shown in Table 3. Clones E 1 and A 26, which differed widely in sensitivity to the Cox 3 and the Miller 3 extracts (Table 2), showed similarly contrasted reactions to the extract of SV 411 at $0.5 \%$. At concentratrations of 2 and $5 \%$, where growth inhibition became marked, this difference was no longer apparent. It seems that these clonal reactions are only visible at low extract concentrations and then only when sporulation is measured as the main cultural response. Host resistance in vivo, after successful infection, is often indicated by the production of lesions bearing no or few conidia, and a demonstration of similar effects in culture may therefore be relevant to the question of host resistance.

Sporulation and growth of Venturia pirina clone $\mathrm{D} 2$ were also strongly inhibited when the concentration of the Conference 3 host-extract was increased beyond $0.5 \%$ (Table 4). Opposite effects were, however, observed with apple extracts at the same and higher concentrations; marked stimulation of sporulation occurred but the conidia were abnormal in shape, being similar to those of $V$. inaequalis. Phloridzin $(0 \cdot 2 \%)$ alone was also highly stimulatory 
of sporulation and may therefore account for this degree of activity, though it was apparently decreased in the presence of the other apple extract components. Arbutin $(0.2 \%)$, the main pear glycoside, was inactive as a stimulator or as an inhibitor of $V$. pirina. Table 4 also demonstrates a striking

Table 4. Inhibition and stimulation of sporulation of Venturia pirina clone $\mathrm{D} 2$ by polyphenolic fractions and major components

Test 25: 9 months after re-isolation 1 ; test 22: 5 months after re-isolation 1. Basal medium NC throughout.

Additions to basal medium NC. Extracts, etc. $(\%, w / v)$

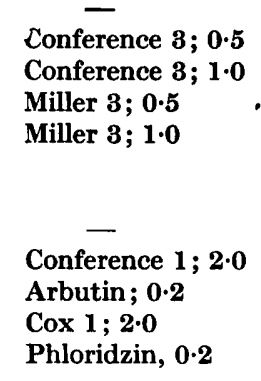

$$
\begin{aligned}
& \text { Conference } 1 ; 2 \cdot 0 \\
& \text { Arbutin; } 0 \cdot 2 \\
& \text { Cox } 1 ; 2 \cdot 0 \\
& \text { Phloridzin, } 0.2
\end{aligned}
$$$$
\begin{aligned}
& \text { Miller } 3 ; 1.0 \\
& \text { Conference } 1 ; 2.0
\end{aligned}
$$

difference between the reactions of $V$. pirina clone D2 to the Conference 1 and 3 extracts. While Conference 3 was strongly inhibitory at $1 \%$, Conference 1 at $2 \%$ increased the length of the lag phase and slightly inhibited growth, but sporulation was greatly increased and normal conidia were produced. This difference must be explicable in terms of chemical composition (Fig. 1), though the modes of action of the various components are as yet unknown. The main difference between the two extracts was that Conference 3 contained arbutin as a major constituent, while in Conference 1 the major constituent was hydroquinone, as a result of the extraction method. Attention has been drawn by Siebs (1955) to the possible significance of hydroquinone in the host relations of $V$. pirina, though in contrast to the present result he suggested that a high concentration of hydroquinone in the host tissues might induce resistance to the pathogen.

\section{Effects of basal media on reactions of Venturia inaequalis}

Reactions of Venturia inaequalis clones E1 and A20, in the presence of three different basal media, to Cox 3 extract $(1 \%)$ and to phloridzin $(0.2 \%)$ are illustrated in Table 5. Clone $\mathbf{E} 1$ was not inhibited by either extract when added to $10 \%$ malt-extract medium, but sporulation of clone A20 in $10 \%$ malt-extract medium was considerably decreased by Cox 3 extract. With medium NC the sporulation of both clones was decreased by each addition, though inhibition of clone A20 was more marked. The third basal medium $3 \mathrm{NC}$, containing three times the normal amount of casein digest, increased the sporulation of clone $\mathbf{A 2 0}$, but the degree of inhibition of both clones by 
phloridzin $(0 \cdot 2 \%, w / v)$ remained the same as in $\mathrm{NC}$ medium. Cox 3 extract, however, was much more inhibitory in these conditions, particularly to clone E1. Thus inhibition was less marked in the presence of a highly-concentrated and complex natural medium, but an increase of the casein digest concentration as in NC did not decrease the degree of inhibition and even had the opposite effect on reactions to the polyphenolic fraction of Cox. Phloridzin was evidently an active component of this fraction, but as the $1 \%$ solution of $\operatorname{Cox} 3$ extract probably contained phloridzin at a concentration higher than $0.2 \%$, this compound was apparently less active in the mixture.

Table 5. Effects of three different basal media on reactions of Venturia inaequalis clones $\mathrm{E} 1$ and A 20 to polyphenolic host constituents

Test 34: 18 months after re-isolation 1 (7 months after re-isolation 2).

\begin{tabular}{|c|c|c|c|c|c|c|c|}
\hline \multirow[b]{2}{*}{ Basal medium } & \multirow[b]{2}{*}{ Additions ( $\%, w / v)$} & \multicolumn{2}{|c|}{ Sporulation } & \multicolumn{2}{|c|}{$\begin{array}{l}\text { Growth } \\
\text { category }\end{array}$} & \multicolumn{2}{|c|}{$\begin{array}{c}\text { Days } \\
\text { incubation }\end{array}$} \\
\hline & & $\mathbf{E 1}$ & A20 & E1 & A20 & E1 & A 20 \\
\hline $10 \%$ Malt-extract & 一 & $0 \cdot 641$ & $0 \cdot 100$ & $\mathbf{3}$ & $\mathbf{3}$ & 17 & 14 \\
\hline $10 \%$ Malt-extract & Cox 3 extract; $1 \cdot 0$ & 0.575 & 0.035 & 3 & 3 & 17 & 14 \\
\hline $10 \%$ Malt-extract & Phloridzin; 0.2 & $0 \cdot 646$ & $0 \cdot 129$ & $\mathbf{3}$ & $\mathbf{3}$ & 17 & 14 \\
\hline $\mathrm{NC}$ & - & $0 \cdot 257$ & $0 \cdot 135$ & 2 & 2 & 19 & 17 \\
\hline NC & Cox 3 extract; $1 \cdot 0$ & $0 \cdot 126$ & 0.024 & 2 & 2 & 10 & 17 \\
\hline NC & Phloridzin; 0.2 & $0 \cdot 115$ & $0 \cdot 081$ & 1 & $\mathbf{2}$ & 19 & 17 \\
\hline $3 \mathbf{N C}$ & - & 0.269 & 0.240 & 2 & 2 & 19 & 17 \\
\hline $3 N C$ & Cox 3 extract; $1 \cdot 0$ & 0.008 & 0.014 & 2 & 2 & 19 & 17 \\
\hline 3NC & Phloridzin; 0.2 & $0 \cdot 123$ & $0 \cdot 174$ & 1 & 2 & 10 & 17 \\
\hline
\end{tabular}

Table 6 shows that in test 36 Conference 3 extract (0.5\%) was strongly inhibitory to Venturia inaequalis clone $\mathrm{E} 1$ and considerably less active against clone A7, in medium NC. Increase of the casein digest concentration in this medium decreased inhibition of clone $\mathrm{E} 1$, the differences between the two clones being no longer apparent. These results show, first, that a polyphenolicfraction of the pear inhibited $V$. inaequalis, in vitro, in contrast with the lack of inhibition of $V$. pirina by an apple extract (Table 4) and, secondly, that an increase of nitrogen in the basal medium decreased this inhibition, though, in the same conditions inhibition by Cox 3 extract was increased (Table 5). The pear extracts were, in general, more toxic in culture to both pathogens than were the apple extracts. The higher content of chlorogenic acid and isochlorogenic acid in the former may partly account for this result. Lack of cross-infection does not seem to be explicable in terms of the cultural reactions to polyphenolic extracts which have been observed.

Venturia inaequalis clones E1 and A7 showed a high degree of tolerance towards trace element concentrations up to twenty times those in NC medium (medium NC.20T). In these conditions clone $\mathrm{E} 1$ was much less inhibited by Cox 3 extract than in test 34 (Table 5), but the reaction of the more susceptible clone A7 was unaltered. In test 36 a higher nitrogen concentration again increased the degree of inhibition of clone $\mathrm{E} 1$ by $\operatorname{Cox} 3$ extract. The reactions of clones A6 and A20 to Cox 3 extract were also observed in media NC.20T and $2 \mathrm{NC} .20 \mathrm{~T}$ in this test. In contrast to the behaviour of clone $\mathrm{E} 1$, clone $\mathrm{A} 6$ 
Table 6. Effects of basal media and storage under paraffin oil on reactions of Venturia inaequalis clones $\mathbf{E} 1$ and $\mathbf{A 7}$, to polyphenolic fractions of apple and pear.

Test 36: 2 months after re-isolation 3 ; test $37: 4$ months after re-isolation 3.

\begin{tabular}{|c|c|c|c|c|c|c|c|}
\hline \multirow[b]{2}{*}{ Basal medium } & \multirow[b]{2}{*}{ Additions $(\%, w / v)$} & \multicolumn{2}{|c|}{ Sporulation } & \multicolumn{2}{|c|}{$\begin{array}{c}\text { Growth } \\
\text { category }\end{array}$} & \multicolumn{2}{|c|}{$\begin{array}{c}\text { Days } \\
\text { incubation }\end{array}$} \\
\hline & & E 1 & $\mathbf{A 7}$ & $\mathbf{E} 1$ & A7 & $\mathbf{E} 1$ & A7 \\
\hline \multicolumn{8}{|c|}{ Test 36} \\
\hline NC & - & $0 \cdot 398$ & $\mathbf{0} \cdot 302$ & 2 & 2 & 21 & 26 \\
\hline NC & $\begin{array}{l}\text { Conference } 3 \text { extract; } \\
0.5\end{array}$ & 0.001 & $0 \cdot 162$ & $\mathbf{1}$ & 2 & 21 & 26 \\
\hline $2 \mathrm{NC}$ & - & $0 \cdot 417$ & $0 \cdot 229$ & 2 & 2 & 21 & 26 \\
\hline $2 \mathrm{NC}$ & $\begin{array}{l}\text { Conference } 3 \text { extract; } \\
0.5\end{array}$ & $0 \cdot 224$ & $0 \cdot 132$ & 3 & 3 & 21 & 26 \\
\hline NC.20T & - & $0 \cdot 398$ & $\mathbf{0} \cdot 123$ & 2 & 2 & 21 & 26 \\
\hline NC.20T & Cox 3 extract; $1 \cdot 0$ & $0 \cdot 316$ & 0.005 & 2 & 3 & 21 & 26 \\
\hline 2NC.20T & - & $0 \cdot 437$ & $0 \cdot 148$ & 2 & 2 & 21 & 26 \\
\hline 2NC.20T & Cox 3 extract; $1 \cdot 0$ & $0 \cdot 209$ & 0.002 & 1 & 2 & 21 & 26 \\
\hline \multicolumn{8}{|c|}{ Test 37} \\
\hline $\mathrm{NC}$ & - & $0 \cdot 251$ & 一 & 2 & - & 17 & 一 \\
\hline NC & $\begin{array}{l}\text { Conference } 3 \text { extract; } \\
0.5\end{array}$ & $0 \cdot 195$ & - & 3 & - & 17 & 一 \\
\hline NC & Cox 3 extract; $1 \cdot 0$ & 0.027 & 一 & 1 & - & 17 & - \\
\hline
\end{tabular}

was considerably less inhibited with the increased nitrogen concentration, and clone A20 (though much less susceptible to Cox 3 extract than was clone A7) also showed no reaction to the increased nitrogen concentration.

In general, a high degree of correlation was observed between the results of similar tests carried out on separate occasions. However, test 36 made 2 months after re-isolation 3, showed that clone A 7 was considerably more resistant and clone $\mathbf{E} 1$ less resistant to Conference 3 extract than in earlier tests before this re-isolation. Two months later (test 37) clone E 1 reacted to Conference 3 extract as had clone $\mathbf{A} 7$ in test 36 and was also very susceptible to Cox 3 extract $(1 \%)$ in $\mathrm{NC}$ medium. It is now thought that, after re-isolation 3, clone $\mathrm{E} 1$ was, while more sensitive to Conference 3 extract, less susceptible to Cox 3 extract (compare test 34), a situation which changed again during further storage of the clones. Unfortunately the factors of increased trace element concentration and possible temporary adaptation to the host substrate, indicated by the reactions to Cox 3 extract, cannot be separated.

\section{Effects of storage under paraffin oil and re-isolation on reactions of Venturia pirina}

Tables 2, 4, 7 and 8 show results obtained with Venturia pirina clone D2, during 17 months' storage under paraffin oil. At the beginning and at the end of this period, clone D2 and other clones were re-isolated from artificially inoculated shoots of Williams' Bon Chrétien pear (re-isolations 1 and 3). Eleven months after re-isolation 1 (before test 28, Table 7) the clones were 
Table 7. Inhibition and stimulation of Venturia pirina clone $\mathrm{D} 2$ by polyphenolic metabolites with two basal media

Test 28 : 12 months after re-isolation 1 (1 month after re-isolation 2); test 29 : 14 months after re-isolation 1 (3 months after re-isolation 2 ).

\author{
Basal \\ medium
} (n)

$\begin{array}{ll}\text { NC } & - \\ \text { NC } & \text { Chlorogenic acid; 0.2 } \\ \text { NC } & \text { Chlorogenic + isochlorogen } \\ \text { NC } & \text { Phloridzin; 0.2 } \\ & \\ \text { NC } & - \\ \text { NC } & \text { Conference 3 extract; } 1 \cdot 0 \\ \text { NC } & \text { Arbutin; 0.4 } \\ \text { NC } & \text { Cox 3 extract; 5.0 } \\ \text { NC } & \text { Phloridzin; 0.2 } \\ \text { 3N3C } & - \\ \text { 3N3C } & \text { Conference 3 extract; } 1 \cdot 0 \\ \text { 3N3C } & \text { Arbutin; 0.4 } \\ \text { 3N3C } & \text { Cox 3 extract; 5.0 } \\ \text { 3N3C } & \text { Phloridzin; 0.2 }\end{array}$

\author{
Growth Days
}

Sporulation category incubation

\section{Test 28}


not increased by Conference 3 extract. An increase of the nitrogen concentration to that of medium $3 \mathrm{NC} .20 \mathrm{~T}$ masked the stimulation of clone $\mathrm{D} 2$ by Conference 3 extract, which now inhibited clone $81^{\prime}$. These results show a trend similar to that shown in test 29 where inhibition of sporulation by Conference 8 extract was increased on medium $3 \mathbf{N ~ 3 C}$, but where the final growth category was somewhat higher.

Table 8. Effects of basal media and storage under paraffin oil on reactions of Venturia pirina, clones D2, P17 and 81', to the Conference 1 and 3 extracts

Test 33: 17 months after re-isolation 1 (6 months after re-isolation 2); test 35 : 18 months after re-isolation 1 (7 months after re-isolation 2$)$.

\begin{tabular}{|c|c|c|c|c|c|c|c|}
\hline \multirow{2}{*}{$\begin{array}{c}\text { Basal } \\
\text { medium }\end{array}$} & \multirow{2}{*}{$\begin{array}{c}\text { Extracts added } \\
(\%, w / v)\end{array}$} & \multicolumn{2}{|c|}{ Sporulation } & \multicolumn{2}{|c|}{$\begin{array}{l}\text { Growth } \\
\text { category }\end{array}$} & \multicolumn{2}{|c|}{$\begin{array}{c}\text { Days } \\
\text { incubation }\end{array}$} \\
\hline & & D2 & P17 & D2 & P17 & D2 & $\mathrm{P} 17$ \\
\hline \multicolumn{8}{|c|}{ Test 33} \\
\hline $\begin{array}{l}\text { NC } \\
\text { NC } \\
\text { NC }\end{array}$ & $\begin{array}{l}-1 \\
\text { Conference } 3 ; 0.5 \\
\text { Conference } 1 ; 2.0\end{array}$ & $\begin{array}{r}0.035 \\
0.066 \\
<0.001\end{array}$ & $\begin{array}{r}0.007 \\
0.019 \\
<0.001\end{array}$ & $\begin{array}{l}\mathbf{2} \\
\mathbf{2} \\
\mathbf{0}\end{array}$ & $\underset{2}{2-3}$ & $\begin{array}{l}20 \\
20 \\
30\end{array}$ & $\begin{array}{l}20 \\
20 \\
30\end{array}$ \\
\hline $\begin{array}{l}\text { NC.2OT } \\
\text { NC.2OT } \\
\text { NC.2OT }\end{array}$ & $\begin{array}{ll}- & \\
\text { Conference } 3 ; 0.5 \\
\text { Conference } 1 ; 2.0\end{array}$ & $\begin{array}{r}0.089 \\
0.085 \\
<0.001\end{array}$ & $\begin{array}{r}0.006 \\
0.009 \\
<0.001\end{array}$ & $\begin{array}{l}\mathbf{2} \\
\mathbf{2} \\
\mathbf{0}\end{array}$ & $\begin{array}{c}2 \\
2-3 \\
0\end{array}$ & $\begin{array}{l}20 \\
20 \\
30\end{array}$ & $\begin{array}{l}20 \\
20 \\
30\end{array}$ \\
\hline \multirow{2}{*}{ NC.2OT } & & \multicolumn{2}{|c|}{ Sporulation } & \multicolumn{2}{|c|}{$\begin{array}{l}\text { Growth } \\
\text { category }\end{array}$} & \multicolumn{2}{|c|}{$\begin{array}{c}\text { Days } \\
\text { incubation }\end{array}$} \\
\hline & & D2 & $81^{\prime}$ & D2 & $81^{\prime}$ & D2 & $81^{\prime}$ \\
\hline \multicolumn{8}{|c|}{ Test 35} \\
\hline $\begin{array}{l}\text { NC.2OT } \\
\text { NC.2OT } \\
\text { NC.2OT }\end{array}$ & $\begin{array}{l}- \\
\text { Conference } 3 ; 0.5 \\
\text { Conference } 1 ; 1.5\end{array}$ & $\begin{array}{r}0.034 \\
0.091 \\
<0.001\end{array}$ & $\begin{array}{r}0.042 \\
0.043 \\
<0.001\end{array}$ & $\begin{array}{l}2 \\
2 \\
1\end{array}$ & $\begin{array}{l}\mathbf{2} \\
\mathbf{2} \\
\mathbf{0}\end{array}$ & $\begin{array}{l}18 \\
18 \\
30\end{array}$ & $\begin{array}{l}18 \\
18 \\
30\end{array}$ \\
\hline $\begin{array}{l}\text { 3NC.2OT } \\
\text { 3NC.2OT } \\
\text { 3NC.2OT }\end{array}$ & $\begin{array}{l}\text { - } \\
\text { Conference } 3 ; 0.5 \\
\text { Conference } 1 ; 1.5\end{array}$ & $\begin{array}{r}0.065 \\
0.068 \\
<0.001\end{array}$ & $\begin{array}{r}0.048 \\
0.028 \\
<0.001\end{array}$ & $\begin{array}{c}2 \\
2-3 \\
1\end{array}$ & $\underset{1}{2-3}$ & $\begin{array}{l}18 \\
18 \\
30\end{array}$ & $\begin{array}{l}18 \\
18 \\
30\end{array}$ \\
\hline
\end{tabular}

Table 9 shows, first, the results of test 36 which was carried out 2 months after re-isolation 3, from Williams' Bon Chrétien. Reactions to Conference 1 and 3 extracts were similar to those in tests 22 and 25, 5 and 9 months after the first re-isolation respectively. Control sporulation of clone D2 was to a higher degree than in test 35 , Conference 3 extract was slightly inhibitory, and Conference 1 extract was stimulatory after an increased lag phase, and with a decrease in final amount of growth. Increase of casein digest in the basal medium slightly increased growth in the presence of Conference 3 extract but had no effect on sporulation. Test 37, 4 months after re-isolation 3 , yielded results comparable with those of test 33, 17 months after re-isolation 1 . Conference 3 extract $(0.5 \% \mathrm{w} / \mathrm{v})$ again markedly increased sporulation, while Conference 1 extract $(1 \% \mathrm{w} / \mathrm{v})$ was intensely inhibitory. Chlorogenic acid increased sporulation of clone D2, thus confirming the indication in test 28 (Table 7).

There appears to be a definite relationship between the cultural reactions described above, particularly to the Conference 1 and 3 extracts, and suc- 
Table 9. Effects of re-isolation of Venturia pirina from artificially-inoculated shoots of Williams, on reactions to polyphenolic metabolites

Test 36 : 2 months after re-isolation 3 ; test 37 : 4 months after re-isolation 3.

\begin{tabular}{|c|c|c|c|c|c|c|c|}
\hline \multirow{2}{*}{$\begin{array}{c}\text { Basal } \\
\text { medium }\end{array}$} & \multirow[b]{2}{*}{ Additions $(\%, w / v)$} & \multicolumn{2}{|c|}{ Sporulation } & \multicolumn{2}{|c|}{$\begin{array}{l}\text { Growth } \\
\text { category }\end{array}$} & \multicolumn{2}{|c|}{$\begin{array}{c}\text { Days } \\
\text { incubation }\end{array}$} \\
\hline & & D2 & P16 & D2 & P16 & D2 & P16 \\
\hline \multicolumn{8}{|c|}{ 'Test 36} \\
\hline NC & - & 0.076 & 一 & 2 & 一 & 19 & - \\
\hline NC & Conference 3 extract; 0.5 & 0.063 & - & 2 & - & 19 & - \\
\hline NC & Conference 1 extract; 1.0 & $0 \cdot 141$ & - & $1-2$ & - & 26 & - \\
\hline $2 \mathrm{NC}$ & 一 & $0 \cdot 078$ & - & 2 & 一 & 19 & 一 \\
\hline $\mathbf{2 N C}$ & Conference 3 extract; 0.5 & $0 \cdot 056$ & 一 & 2-3 & - & 19 & - \\
\hline $2 \mathrm{NC}$ & Conference 1 extract; $1 \cdot 0$ & $0 \cdot 129$ & - & 1-2 & 一 & 26 & - \\
\hline \multicolumn{8}{|c|}{ Test 37} \\
\hline NC & - & 0.055 & 0.010 & 2 & 2 & 19 & 17 \\
\hline NC & Conference 3 extract; 0.5 & $0 \cdot 132$ & 0.085 & $\mathbf{2}$ & 2 & 19 & 17 \\
\hline NC & Conference 1 extract; 1.0 & $0 \cdot 001$ & 0.001 & $\mathbf{1}$ & $\mathbf{0}$ & 25 & 25 \\
\hline NC & Cox 3 extract; $1 \cdot 0$ & 0.839 & $0 \cdot 275$ & 2 & $\mathbf{2}$ & 19 & 17 \\
\hline NC & Chlorogenic acid; 0.5 & $0 \cdot 087$ & $0 \cdot 080$ & 2 & 2 & 19 & 17 \\
\hline
\end{tabular}

cessive re-isolations of the pathogen from Williams. A gradual change occurred during the 18 months' storage under paraffin oil between re-isolations 1 and 3, which was not influenced by the mono-conidial transfer of the stock cultures. The sudden reversal after re-isolation 3 and the rapid return to the type of reaction observed before it are also noteworthy. It was shown by Kirkham (1957) that the pathogenicity of Venturia pirina may decline more rapidly during storage in culture than the pathogenicity of $V$. inaequalis, and that the rate of this decline increased after each successive re-isolation from Williams. There seems to be a definite parallel between the stability of the pathogenic capabilities of $V$.pirina on Williams and reactions to polyphenolic host constituents, which strongly suggests that the reactions of a given clone to these compounds, in relation to other nutritional factors, may be important in the determination of pathogenicity.

\section{Decomposition of polyphenolic host metabolites by Venturia inaequalis and $\mathrm{V}$. pirina in artificial culture}

Intense colour reactions resulted from the presence of the extracts and components in the various basal media during the lag phases of growth of both pathogens. Chromatographic examination of media containing single metabolites showed that they were decomposed with the formation of high molecular weight products. Fig. 2 shows chromatograms of stages in the decomposition of arbutin and chlorogenic acid by Venturia inaequalis, clones E1 and A7. Spots visible in ultraviolet light are outlined in pencil. Table 10 shows the comparative amounts of decomposition visible on the chromatograms. Chlorogenic acid was destroyed more rapidly than arbutin, clone $\mathrm{E} 1$ was more active than clone $\mathbf{A 7}$, and increase of casein digest concentration 
Table 10. Venturia inaequalis. Decomposition of arbutin and chlorogenic acid in two basal media by clones $\mathrm{E} 1$ and A7 (see Pl. 1, Fig. 2)

Chro-
matogram

no.

$$
\left.\begin{array}{l}
1 \\
2 \\
3 \\
4 \\
5 \\
6
\end{array}\right\}
$$$$
\left.\begin{array}{r}
7 \\
8 \\
9 \\
10 \\
11 \\
12
\end{array}\right\}
$$

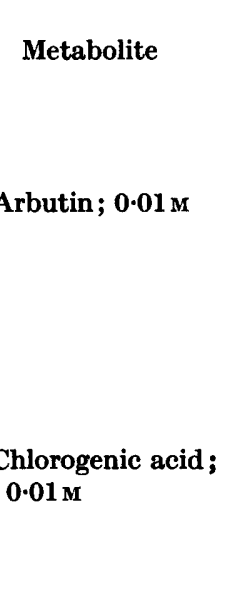

$$
\begin{gathered}
\text { Clone of } \\
V . \text { inaequalis }
\end{gathered}
$$

E1

(Uninoculated
control)

$\left\{\begin{array}{c}\text { A7 } \\ \text { E1 } \\ \text { (Uninoculated } \\ \text { control) } \\ \text { A7 }\end{array}\right.$

$\left\{\begin{array}{c}\text { E1 } \\ \text { (Uninoculated } \\ \text { control) } \\ \text { A7 } \\ \text { E 1 } \\ \text { (Uninoculated } \\ \text { control) } \\ \text { A7 }\end{array}\right.$

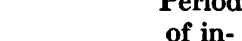

Basal cubation Degree of medium (days) decomposition*

NC

$\mathrm{NC}$

NC

3NC

3NC

3NC

$\mathrm{NC}$

$\mathrm{NC}$

NC

$\mathbf{3 N C}$

3NC

3NC
$8 \quad+++$

8 Trace

$8 \quad++$

$8 \quad+++$

8 Trace

$8+$

5

$\mathbf{5}$

$+++$

Trace

$++$

$++$

Trace

$++$

$*++++$ indicates maximal decomposition of metabolite.

in the basal medium slowed down the rate of decomposition to some extent. These observations may be compared with the facts that clone A7 was more susceptible to inhibition by the extracts than clone $\mathrm{E} 1$, and that higher concentrations of nitrogen sometimes increased the inhibitory activities of the extracts. The chromatograms showed that during the course of decomposition, various intermediates were present in the basal media. One of these was identified as hydroquinone, temporarily present as a result of the destruction of arbutin by $V$. pirina. When decomposition was complete the metabolites and intermediates finally disappeared completely, leaving only compounds of high molecular weight which remained on the starting line. Only very slight breakdown occurred during incubation of the uninoculated controls. Decomposition of arbutin also occurred in the presence of a culture filtrate of clone $\mathrm{E} 1$, thus demonstrating the exogenous activity of an enzyme system.

These results show that both Venturia inaequalis and V. pirina produce polyphenoloxidase enzyme systems capable of destroying compounds inhibitory to normal development. Nevertheless, it was found that, even after complete breakdown, inhibition of sporulation was frequently recorded at the end of the incubation period. This may have been due to changes in the metabolism of the fungi induced by the presence of these compounds or to the activity of undetected intermediates. 


\section{DISCUSSION}

It is clear from the foregoing experiments that polyphenolic host metabolites are of considerable significance in the metabolism of the pathogens in artificial culture, and the results suggest the possibility of their operation as resistance factors. In both cases there are indications of optimal balance mechanisms between the polyphenols of the host and the nitrogenous constituents of the basal media, though other nutritional factors are also clearly of importance. These mechanisms seem to be highly complex, needing further elucidation before they will be explicable in terms of the metabolism of the hosts and the pathogens. The role of the polyphenoloxidases in these systems is also of considerable interest. Johnson \& Schaal (1952) reported that tyrosinase converts chlorogenic acid to the quinone in damaged potato tissue, and that the latter compound may be important in resistance to Actinomyces scabies. It has also been suggested that a polyphenoloxidase produced by the host may play a part in the resistance of tomato plants to Fusarium oxysporum (Davis, Waggoner \& Dimond, 1953).

The fact that Venturia inaequalis and $V$. pirina are not pathogenic on pear and apple, respectively, even though infection may occur, certainly does not seem to be explicable in terms of polyphenolic compounds alone. As Walker \& Stahman (1955) stated, they may be subsidiary factors modifying a basic disease reaction and working in relation to other host metabolites. In that case they will, as the results suggest, be of importance in the determination of pathogenicity and varietal resistance in these two diseases. This study confirms and extends those of Wiltshire (1915), Johnstone (1981) and Rudloff (1934), each of whom suggested a biochemical basis for resistance to Venturia species. Nevertheless, it must be remembered that the reactions described above occurred in an abnormal environment and do not necessarily demonstrate the operation of resistance mechanisms in vivo. It can only be shown that cultural work is leading to relevant observations when direct evidence for the operation of similar mechanisms under natural conditions is obtained by extension of the work to the living host plants.

The author wishes to thank Dr R. V. Harris for his advice and interest during the course of the work, the late Dr A. E. Bradfield and Dr A. E. Flood for advice on plant extraction methods and for running the chromatograms, Miss Jean Richardson for technical assistance and Mr G. M. Jolly for the statistical analysis of the results.

\section{REFERENCES}

Bradfield, A. E. \& Flood, A. E. (1949). The organic constituents of fruit plants. 1. An outline of a method of examination of the water and alcohol soluble constituents. Rep. E. Malling Res. Sta. p. 100.

Campbell, P. N., Work, T. S., \& Mellanby, E. (1951). The isolation of a toxic substance from agenized wheat flour. Biochem. J. 48, 106.

Davis, D., Waggoner, P. E. \& Dimond, A. E. (1953). Conjugated phenols in the Fusarium wilt syndrome. Nature, Lond. 172, 959.

Johnson, G. \& SchaAl, L. A. (1952). Relation of chlorogenic acid to scab resistance in potatoes. Science, 115, 627 . 
JoHNSTONE, K. H. (1931). Observations on the varietal resistance of the apple to scab (Venturia inaequalis, Aderh.) with special reference to its physiological aspects. Part II. J. Pomol. 9, 195.

Kirkham, D. S. (1954). Significance of the ratio between the water-soluble aromatic and nitrogen constituents of apple and pear in the host-parasite relationships of Venturia species. Nature, Lond. 173, 690.

Kirkham, D. S. (1956). A culture technique for Venturia spp. and a turbidimetric method for the estimation of comparative sporulation. Nature, Lond. 178, 550.

KIRKHAM, D. S. (1957). Relationships between cultural characters and pathogenicity in Venturia inaequalis and Venturia pirina. J. gen. Microbiol. 16, 360.

Leben, C. \& KeItr, G. W. (1948). Venturia inaequalis (Cke.) Wint. V. The influence of carbon and nitrogen sources and vitamins on growth in vitro. Amer. J. Bot. 35, 337.

Rudloff, C. F. (1934). Venturia inaequalis (Cooke) Aderhold. 1. Der Einfluss des Nährbodens auf den Pilz und die Erhaltung seiner Pathogenität. Gartenbaureiss. 9, 65.

Stebs, E. (1955). Untersuchungen über die Schorfresistenz von Birnen. 111. Stofflicher Hinweis auf die Grundlagen der Blattschorfresistenz. Phytopath. Z. 23, 37.

Walker, J. C. \& Stahman, M. A. (1955). Chemical nature of disease resistance in plants. Annu. Rev. Pl. Physiol. 6, 851.

WiLtshire, S. P. (1915). Infection and immunity studies on the apple and pear scab fungi (Venturia inaequalis and V. pirina). Ann. appl. Biol. 1, 335.

\section{EXPLANATION OF PLATE}

Fig. 1. Chromatograms of three polyphenolic fraction extracts each of Cox (Cx), Miller (M), Williams (W) and Conference (C). Extracts 1 and 3 are of young leaves, extract 2 is of mature leaves. Identifled components are numbered as follows: arbutin (1), chlorogenic acid (2), phloridzin (8), phloretin (4), isochlorogenic acid (5) and hydroquinone (6).

Fig. 2. Chromatograms of stages in the decomposition of arbutin and chlorogenic acid by Venturia inaequalis, clones $\mathrm{E} 1$ and A7. The significance of the numbers $1-12$ is explained in Table 10. 
Journal of General Microbiology, Vol. 17, No. 1

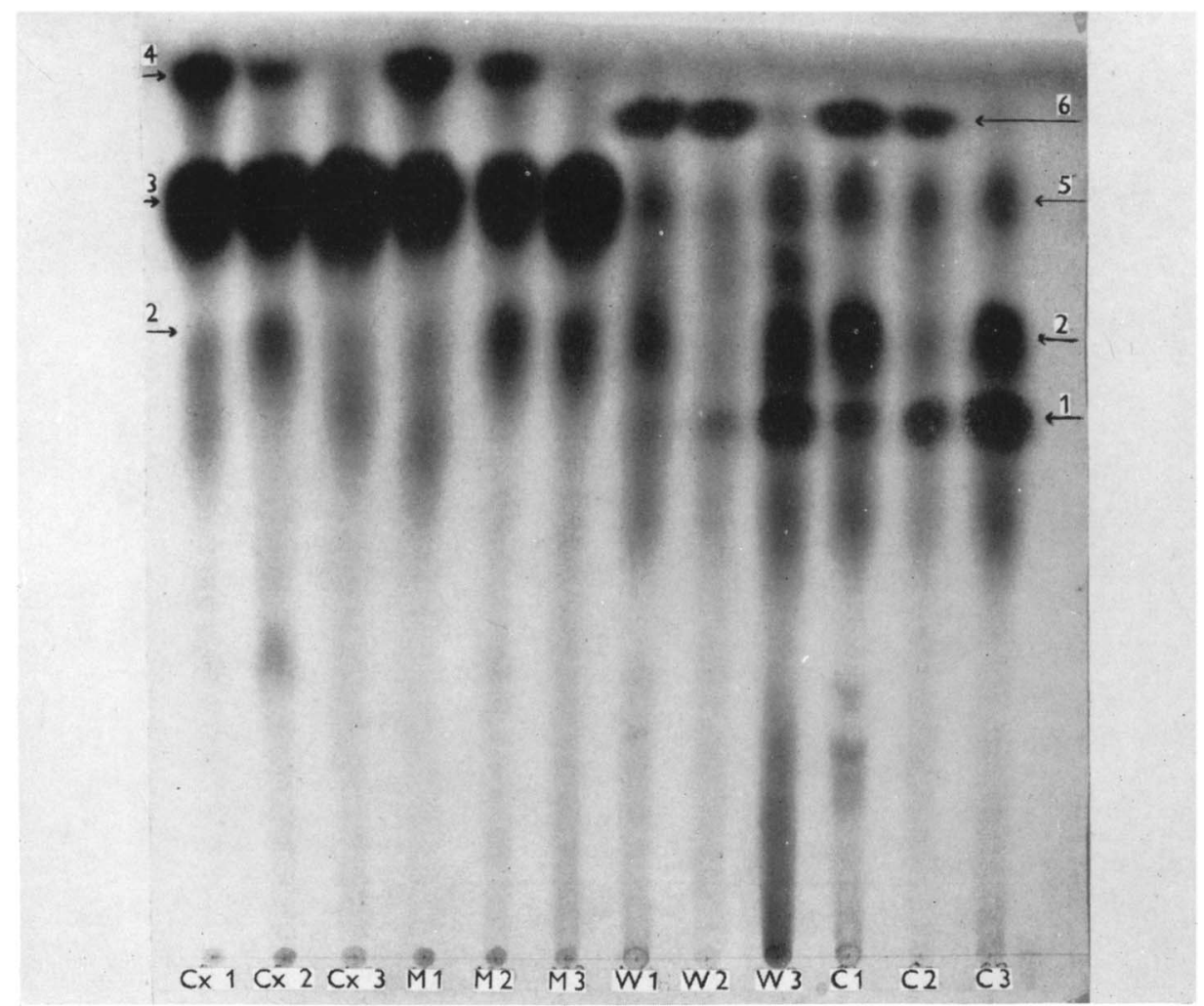

Fig. 1

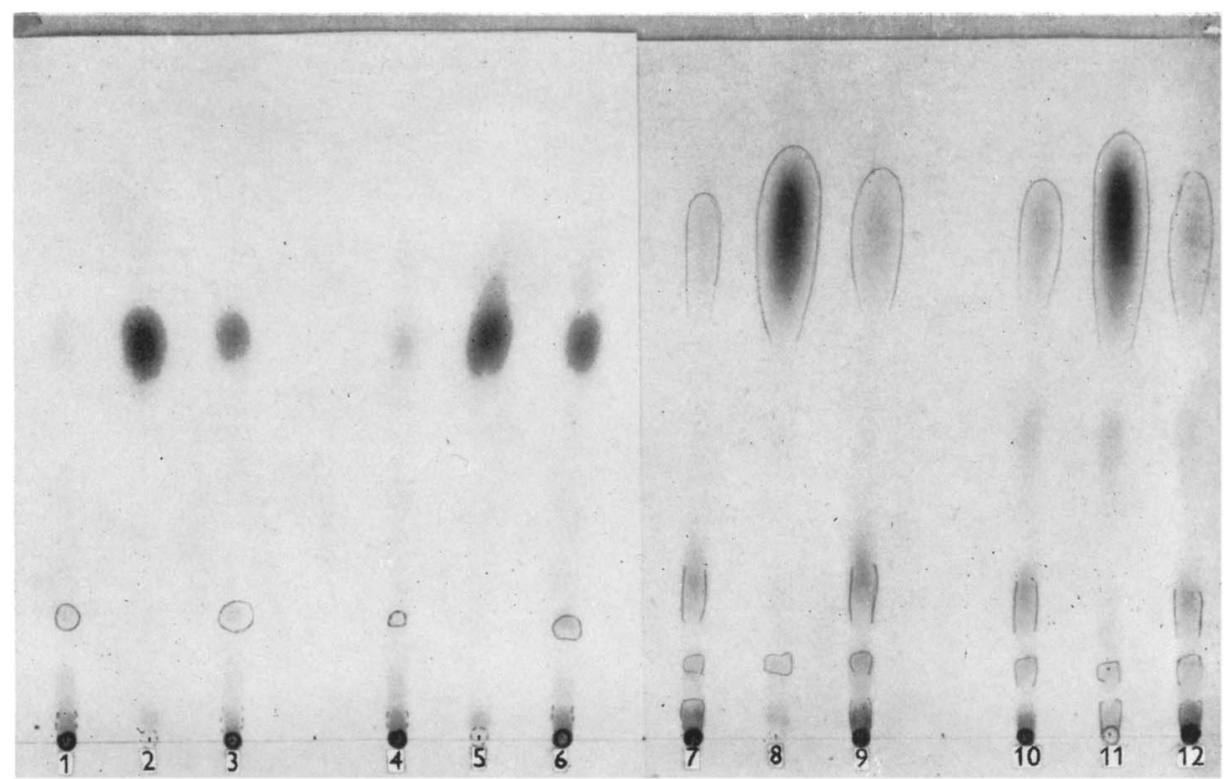

Fig. 2

D. S. Kirkham-Venturia species and host métabolites. Plate 1 